\title{
Automation Control System against Driver Falling Asleep in Traffic
}

\author{
Ilya S. Dymov \\ Electric Drive and Automation of Industrial Units Department \\ Novosibirsk State Technical University \\ Novosibirsk, Russia \\ dymov.2010@corp.nstu.ru
}

\author{
Denis A. Kotin \\ Electric Drive and Automation of Industrial Units Department \\ Novosibirsk State Technical University \\ Novosibirsk, Russia \\ d.kotin@corp.nstu.ru
}

\author{
Roman E. Derevyanko \\ Electric Drive and Automation of Industrial Units Department \\ Novosibirsk State Technical University \\ Novosibirsk, Russia \\ romder3@yandex.ru
}

\begin{abstract}
The paper is devoted to the development of a new automation recognition and warning system against driver falling asleep in traffic. The issue of the physical condition of professional drivers on the trip is considered on the part of both efficiency and quality of determination, and in terms of improving overall road safety. The existing and widely used devices for determining the transition to the sleep phase of behind at the wheel drivers are analyzed. Their advantages and disadvantages are detected. It has been established that the main negative factor preventing the mass introduction of pre-existing warning systems is the need to put on one or another monitoring device before starting the movement. The carried out design and research work offers a comprehensive monitoring of the physical and physiological state of a person at the wheel as a new way of preventing his falling asleep during the movement. The variants of algorithmic implementation are proposed for consideration can be applied in freight and passenger long-distance vehicles. Two contrasting options of the automatic control status of the driver physical condition are considered. The first approach proposes the use of sensors of the biometric parameters of the body, pulse, body temperature, and hands on the wheel pressure sensors. The second is using tracking cameras-detectors. Both for the first and the second versions of the automation system, a toolset of control devices installed inside the vehicle and have no physical, so irritating action on the driver. A software approach to eliminate false positives of the proposed devices is developed. The paper considered the flow diagrams of the automatic systems and a logical structure of analysis and decision-making. A set of impacts intended for driver's awakening is proposed. A conclusion is made about the technical prospects of the proposed approach to the design of automated systems.
\end{abstract}

Keywords - component automation system, warning falling asleep, transportation vehicle, driver physical condition sensors, safety of traffic.

\section{INTRODUCTION}

The issue of the safety of drivers and passengers on the roads is, to date, sharply discussed. Analysis of the statistics of accidents of long distance passenger and cargo transport showed a high percentage of incidents that occurred as a result of the driver falling asleep during the movement, both at night and in the early morning.

However, sleep is not a monotonous trip from the outside world and a period of reduced activity, but a special state of the organism characterized by a regular successive change of certain activity in the form of cycles, stages and phases. Sleep consists of two successive phases - slow and fast, which together constitute one cycle. The episode of slow sleep consists of several stages, which differ in the activity of the brain. At the initial stage of sleep, there is so-called drowsiness or falling asleep. There is the interval of time which is only 300-600 seconds and within which the driver can get into a serious accident [1].

\section{MATERIALS AND METHODS OF ALERTING THE DRIVER OF HIS CONDITION}

Every professional motorist prefers his, as it seems to him, effective methods of combating sleep. The most common ways to "stay awake" among drivers of passenger and freight vehicles are the following: the use of loud music at the regular car stereos; the use of invigorating caffeinated preparations, such as energy drinks, green tea and coffee [2]. But the listed measures are ineffective, especially in those cases when a person has malaise, fatigue or stress. To solve the above problem, it becomes necessary to develop intelligent automated systems and complexes that would warn the driver about the oncoming of drowsiness.

In the past few years the world's leading automakers, such as Toyota, General Motors, Volvo are actively introducing the systems for prevention of the driver falling asleep at the wheel (Table.1). 
TABLE I. WARNING METHODS AGAINST DRIVER FALLING ASLEEP ON THE MOVE

\begin{tabular}{|l|c|}
\hline \multicolumn{1}{|c|}{$\begin{array}{c}\text { Table } \\
\text { Head }\end{array}$} & \multicolumn{1}{c|}{ Principle of the device operation } \\
\hline Toyota & $\begin{array}{c}\text { Monitoring the position of the eyeballs and } \\
\text { the frequency of oscillations of the driver's } \\
\text { eyelids through the onboard computer and the } \\
\text { camera }\end{array}$ \\
\hline $\begin{array}{l}\text { GeneralM } \\
\text { otors }\end{array}$ & $\begin{array}{l}\text { Control with the help of motion detection } \\
\text { cameras that fix the change in the position of } \\
\text { the head and the sticking of the driver's eyes }\end{array}$ \\
\hline Volvo & $\begin{array}{c}\text { Identification of the driver's condition by } \\
\text { tracking the eye movement with the help of } \\
\text { infrared sensors located in the car's cabin }\end{array}$ \\
\hline
\end{tabular}

At the same time, the modern electronic equipment market represents a large number of devices that could assess the driver's condition and indicate the impossibility of continuing the movement (Table 2). All of them have some or other disadvantages, limiting their mass use $[3,4]$.

The principle of operation of technologies which are on the market has a similar character - monitoring the driver's physical condition, revealing deviations from the parameters of the normal state and warning $[5,6]$. However, when using the options discussed, not all devices are able to accurately determine the driver's condition and respond in advance. But the main drawback is that the driver always needs to wear a certain device before going out. The presence of a human factor that affects equipment of this kind adversely affects the operation of the warning system as a whole.

\section{RESULTS AND DISCUSSION}

\section{A. System using driver's sensors}

In order to eliminate the shortcomings of existing analogues and improve the safety of the participants of the movement due to the rationality and availability of automatic detection systems for the falling asleep of drivers, the design and research work to create own identification and alert system were carried out. The developed way to monitor the driver's condition is that the automated system performs continuous monitoring of the physiological state of the driver, focusing on signals that come from the sensors located inside the vehicle's interior (Fig. 1).

As a driver identification device, a set of sensors is used: a pulse sensor, a temperature sensor and a hand pressure sensor on the steering wheel. All these measuring instruments are located on the steering wheel braid of the vehicle. The driver feedback signals are sent to the control system, where they are analyzed, and a decision to provide warning light and sound signals is made.

In the process of preparing the system for the direct use in the $\mathrm{V}$, the microcontroller records possible-acceptable (reference) indicators of the driver's condition. In the process of work, the reference values are compared with the actual state indicators. In this case, the base values are corrected down during the movement from the initially introduced ones, depending on the current driving speed, in accordance with the following relations (see Table 3 ).

TABLE II. WARNING DEVICES AGAINST DRIVER FALLING ASLEEP ON THE MOVE

\begin{tabular}{|c|c|c|}
\hline Title & Operation Principle & Disadvantages \\
\hline Vigo & $\begin{array}{l}\text { Tracking the } \\
\text { regularity and } \\
\text { frequency of eye } \\
\text { movement, as well } \\
\text { as their blinking } \\
\text { when using infrared } \\
\text { sensors and an } \\
\text { accelerometer }\end{array}$ & $\begin{array}{l}\text { The need for a } \\
\text { separate Bluetooth } \\
\text { data transfer device, } \\
\text { which is not included } \\
\text { in the basic set }\end{array}$ \\
\hline StopSleep & $\begin{array}{l}\text { Continuous } \\
\text { measurement of the } \\
\text { conductivity of the } \\
\text { driver's skin on the } \\
\text { fingers }\end{array}$ & $\begin{array}{l}\text { Limitation of the } \\
\text { movement of the } \\
\text { fingers in connection } \\
\text { with the specificity of } \\
\text { wearing on two } \\
\text { fingers. } \\
\text { Inconvenience of } \\
\text { driving the vehicle } \\
\text { with a manual } \\
\text { gearbox }\end{array}$ \\
\hline VIGITON & $\begin{array}{l}\text { Continuous } \\
\text { monitoring of the } \\
\text { physiological state } \\
\text { of the driver. Alerts } \\
\text { other traffic } \\
\text { participants that the } \\
\text { vehicle is } \\
\text { uncontrollable - the } \\
\text { inclusion of } \\
\text { external emergency } \\
\text { light and sound } \\
\text { signals }\end{array}$ & $\begin{array}{l}\text { Large weight and } \\
\text { dimensions. The need } \\
\text { to install up to } 7 \\
\text { interconnected } \\
\text { devices directly in } \\
\text { front of the driver, } \\
\text { limiting the overview }\end{array}$ \\
\hline Antisleep & $\begin{array}{l}\text { Response to tilt the } \\
\text { head down }\end{array}$ & $\begin{array}{l}\text { Difficulty adjusting } \\
\text { the initial level of the } \\
\text { tilt due to differences } \\
\text { in the body of various } \\
\text { vehicles. No response } \\
\text { to lateral head } \\
\text { inclinations }\end{array}$ \\
\hline $\begin{array}{l}\text { Avita } \\
\text { «Anti sleep» }\end{array}$ & $\begin{array}{l}\text { Listening and } \\
\text { determination of } \\
\text { heart rate rhythms }\end{array}$ & $\begin{array}{l}\text { Extremely low } \\
\text { operating time } \\
\text { without additional } \\
\text { charging. }\end{array}$ \\
\hline
\end{tabular}




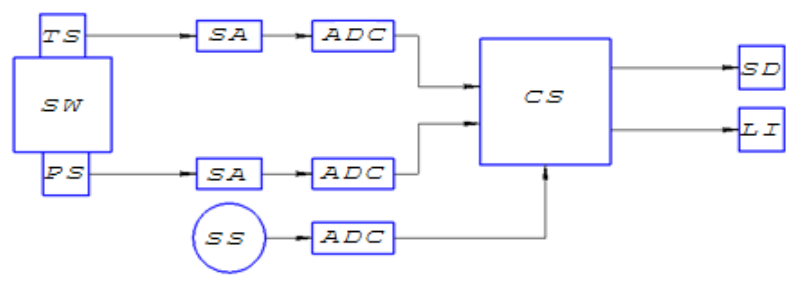

Fig. 1. Flow diagram of warning sensors system against driver falling asleep on move.

Fig. 1 denotes: SW - steering wheel; TS - temperature sensor; PS-pulse sensor; SS - speed sensor (V speedometer); SA - signal amplifiers; ADC - analog-digital converter; CS control system (microcontroller); SD - sound device; LI - light indication.

TABLE III. CORRECTION FACTORS

\begin{tabular}{|c|c|c|c|c|}
\hline \multirow[b]{2}{*}{ Options } & \multirow[b]{2}{*}{$\begin{array}{l}\text { Reference } \\
\text { values, } \\
\text { r.u. }{ }^{a}\end{array}$} & \multicolumn{3}{|c|}{ Actual values, r.u. } \\
\hline & & $\begin{array}{c}\text { Vehicle speed } \\
\text { up to } 60 \mathrm{~km} / \\
\mathrm{h}\end{array}$ & $\begin{array}{l}\text { Vehicle speed } \\
\text { from } 60 \mathrm{~km} / \mathrm{h} \\
\text { up to } 90 \mathrm{~km} / \mathrm{h}\end{array}$ & $\begin{array}{c}\text { Vehicle speed } \\
\text { over } 90 \mathrm{~km} / \mathrm{h}\end{array}$ \\
\hline $\begin{array}{l}\text { Body } \\
\text { temperature }\end{array}$ & 1 & $\begin{array}{l}\text { not less } \\
\text { than } 0,97\end{array}$ & $\begin{array}{c}\text { not less } \\
\text { than } 0,98\end{array}$ & $\begin{array}{l}\text { not less } \\
\text { than } 0,99\end{array}$ \\
\hline Heartbeats & 1 & $\begin{array}{l}\text { not less } \\
\text { than } 0,87\end{array}$ & $\begin{array}{l}\text { not less } \\
\text { than } 0,9\end{array}$ & $\begin{array}{l}\text { not less } \\
\text { than } 0,93\end{array}$ \\
\hline $\begin{array}{l}\text { Pressure on } \\
\text { the steering } \\
\text { wheel }\end{array}$ & 1 & $\begin{array}{l}\text { not less } \\
\text { than } 0,5\end{array}$ & $\begin{array}{l}\text { not less } \\
\text { than } 0,7\end{array}$ & $\begin{array}{l}\text { not less } \\
\text { than } 0,9\end{array}$ \\
\hline
\end{tabular}

\section{B. The system without using the driver's condition sensors}

An alternative approach for solving the problem of determining and preventing the driver from falling asleep during the journey may be the use of two interlocking chambers located on the inner arches of the vehicle interior opposite the driver's seat [7]. The essence of this approach is that the system performs continuous monitoring of the position of the pupils of the driver (Fig. 2).

Let us avoid combining SI and CGS units, such as current in amperes and magnetic field in worsteds. This often leads to confusion because equations do not balance dimensionally. If you must use mixed units, clearly state the units for each quantity that you use in an equation.

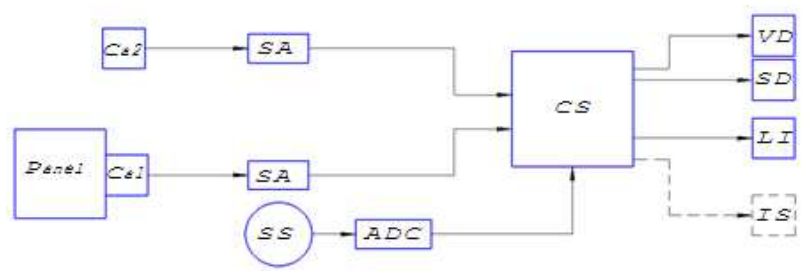

Fig. 2. Flow diagram of warning sensorless system against driver falling asleep on move.

Fig. 2 denotes: SS - speed sensor (V speedometer); SA signal amplifier; ADC - analog-digital converter; CS - control system (microcontroller); VD - vibrating device; SD- sound device; LI - light indication; Ca1 - camera 1; Ca2 - camera 2; IS - injection system.

Each camera captures the position of the pupil of the driver and transmits information about their presence in a given range of visibility into the digital control system. In the absence of pupils in the field of view of one of the cameras, another question is taken. Provided that the information on the absence of pupils in the area of validity is confirmed on the second camera, the driver is alerted by light, sound and vibration signals, as well as a refreshing odor like "mint". Automated system without the use of sensors, as well as the proposed sensor system (see Fig. 1) determines the intensity of the warning signals depending on the speed of movement of the vehicle.

\section{The system without using the driver's condition sensors}

In order to minimize the presence of false responses in the system, a warning about the occurrence of a nap condition is provided only if all the deviations from the driver's vigor state are combined. In the presence of deviation of any one (or two) parameters from the reference values, only a light indication occurs, fixing the possible beginning of falling asleep [7]. The algorithm of the proposed device for preventing drivers from falling asleep is shown in Fig. 3. 


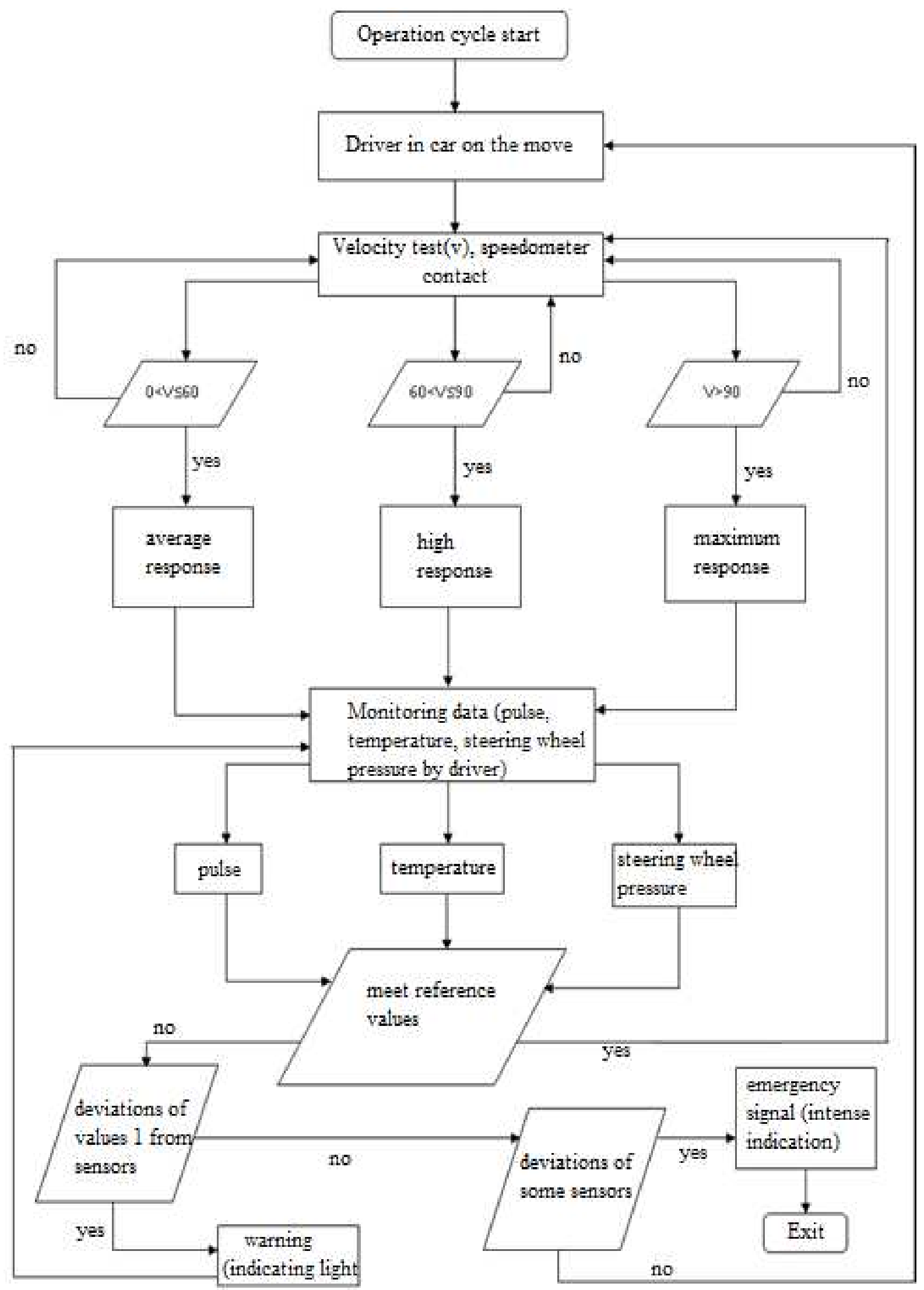

Fig. 3. A logical structure of analysis and decision-making about the driver falling asleep. 


\section{CONCLUSION}

The paper proves the expediency of using automated systems and complexes to prevent drivers falling asleep during the movement of the vehicle. Improving road safety, life and health of traffic participants have the highest priority.

Analyzing the results of the proposed approaches to the design of the system for determining and preventing the driver from falling asleep while driving, the following conclusions can be drawn:

1) The modes of multifunctional control of the driver's status of the vehicle are offered, both with the use of sensors of its physical state and with their absence.

2) The adaptation of each of the proposed automated systems to the value of the current speed of movement of the vehicle is considered.

3) The minimization of possible false responses of devices by sequential determination of the physiological state of the driver is proposed.

The hardware implementation of the presented methods and approaches should be the next step in the study. And also the study of a prototype model on a real vehicle.

\section{References}

[1] A.M. Petrov, A.R. Giniatullin, Neurobiology of sleep, Modern look: A Tutorial, Kazan: KSMU, 2012. 109 p.

[2] A.A. Gorshenin, E.Y. Lipatov, "Analysis of devices for monitoring the condition of the driver", News VSTU,. vol. 10(113). pp. 51-53, 2013.

[3] K.S. Chubarev, "New services in auto-service", Technical and technological problems of service, vol. 3(13). pp. 108-110, 2010.

[4] N.V. Korneev, A.V. Grebennikov, "Software and hardware implementation of on-board operational-relevant expert systems for transport", News of the Samara scientific center of the Russian Academy of Sciencesvol, vol. 16(4). p. 116-122, 2014.

[5] T.G. Tlupova, "A new method for estimating the effect of the pupil's value on the resolution of vision when the light conditions chang", Journal of new medical technologies, vol. 15(3). pp. 126-127, 2008.

[6] I.B. Lashkov, A.V. Smirnov, A.M. Kashevnik, "Research and development of an approach to building an intelligent mobile service for automated support of the vehicle driver", Scientific and Technical Journal of Information Technologies, Mechanics and Optics, vol. 15 (6). pp. 1130-1138, 2015.

[7] Ilya S. Dymov, Denis A. Kotin, "Signal-Adaptive Controller for Micro Electric Drive Rotor Radial Displacement Updating", pp. 572 - 578, 29 June - 3 July, 2017 [18 International Conference of Young Specialists on Micro/Nanotechnologies and Electron Devices, p. 630, 2017]. 